\title{
Disinflation and the Supply Side
}

\author{
Pierre-Richard Agénor* and Lodovico Pizzati* \\ Revised version: October 4, 2003 \\ Final version: May 19, 2004
}

\begin{abstract}
This paper studies the dynamics associated with permanent and temporary reductions in the devaluation rate. The analysis uses an intertemporal optimizing model of a small open economy with imperfect capital markets and endogenous labor supply. With a constant capital stock, the model predicts an initial reduction in real wages and an expansion in output. Consumption falls on impact but increases afterward. In addition, with a temporary shock, a current account deficit emerges and a recession sets in at a later stage. With endogenous capital accumulation, numerical simulations show that the model is also capable of predicting a boom in investment.
\end{abstract}

JEL Classification Numbers: E44, F32, F34

Keywords: Disinflation; imperfect capital markets; investment dynamics

*The World Bank, 1818 H Street, Washington DC 20433. We are grateful to anonymous referees for very helpful comments and suggestions. Copies of unpublished Appendices A, $\mathrm{B}$ and $\mathrm{C}$ are available upon request. The views expressed in this paper do not necessarily represent those of the World Bank. 


\section{Introduction}

Stabilization programs based on the use of the exchange rate as a nominal anchor have often been characterized by a boom-recession cycle, a real exchange rate appreciation, and persistent current account deficits. In the Southern Cone "tablita" experiments of the late 1970s in Argentina, Chile, and Uruguay, for instance, aggregate consumption increased in real terms by an average of ten percent in the first year following the implementation of the plan, before slowing down (see Végh (1992) and Calvo and Végh (1994)). An expansion in domestic investment (often associated with an increase in imports of capital goods) and a rise in labor supply have also been observed in some of these programs (Roldós (1995), and Rebelo and Végh (1997)). As documented by Fischer, Sahay, and Végh (2002) the output and domestic absorption booms appear to have been observed in both successful and failed exchange rate-based stabilization attempts, whereas money-based stabilization programs have generally been accompanied by a protracted recession. ${ }^{1}$

Various theories have been proposed to explain the boom-recession cycle in exchange-rate based stabilization programs. One branch of literature, developed in particular by Helpman and Razin (1987), emphasizes the wealth effects of stabilization programs. A second approach is the temporariness hypothesis, developed by Calvo and Végh (1993). A key feature of this approach is its emphasis on the interactions between the lack of credibility (modeled as a temporary policy change) and intertemporal substitution effects. A transitory reduction in the devaluation rate is equivalent to a temporary fall in present prices relative to the future, and induces an intertemporal substitution in consumption toward the present-leading to a rise in output, real

\footnotetext{
${ }^{1}$ Research by Easterly (1996) and Gould (1996) has shown, however, that output and absorption tend to rise at the inception of both money-based (MBS) and exchange-rate based (ERBS) stabilization programs. Gould (1996) for instance found that real output growth tends to increase in all the programs in his sample (except for the 1985 stabilization in Bolivia). Output growth, nevertheless, appears to be higher in the immediate aftermath of ERBS compared to MBS. See also Hamann (2001) for a critical discussion of the "stylized facts" associated with exchange rate-based stabilization.
} 
exchange rate appreciation, and a current account deficit. However, evidence on the temporariness hypothesis is mixed. The econometric study by Reinhart and Végh (1995) suggested that although it can explain the behavior of consumption in some of the programs implemented in the 1980s, it is less useful for understanding the tablita experiments of the late 1970s in Argentina, Chile, and Uruguay. Given the low intertemporal substitution parameters estimated for these countries, nominal interest rates would have had to fall by substantially more than they actually did to account for a sizable fraction of the consumption boom recorded in the data. A third approach, developed by De Gregorio, Guidotti, and Végh (1998), emphasizes the role of durable goods accumulation in generating a consumption boom-bust cycle, without resorting to lack of credibility.

A fourth approach to the behavior of consumption and output in exchangerate based programs emphasizes the supply-side effects of stabilization. Roldós (1995), in particular, analyzed these effects in a dependent-economy model with physical capital (which plays a dual role as a financial asset and a production input), endogenous labor supply, and a cash-in-advance constraint (following Stockman (1981)) on purchases of both consumption and capital goods. Roldós showed that, as a result of the cash-in-advance constraint, inflation creates a wedge between the real rate of return on foreign-currency denominated assets and that of domestic-currency denominated assets - which include money and capital. ${ }^{2}$ A stabilization program based on a permanentand thus fully credible, in the Calvo-Végh sense - reduction in the devaluation rate reduces this wedge (by lowering inflation) and leads to an increase in the desired capital stock in the long run. In the short run, consumption and investment increase, causing a real appreciation, a current account deficit, and an increase in output of home goods. During the transition period, firms increase their purchases of capital goods and their capital stock, drawing labor resources into the (capital-intensive) tradables sector, raising wages and

\footnotetext{
${ }^{2}$ Uribe (1997) also analyzes the dynamics of exchange-rate based stabilization in a model in which inflation influences the rate of return on domestic capital. The assumption that the investment good is a "cash good" in these models is, however, not very intuitive.
} 
leading to further appreciation of the real exchange rate. Over time, the increase in output of tradable goods lowers the initial current account deficit generated on impact by the increase in aggregate demand. In a subsequent paper, Roldós (1997) focused on a gradual and permanent reduction in the nominal devaluation rate, as in Obstfeld (1985). He showed that this policy leads to an initial boom when the intertemporal elasticity of substitution in labor supply is larger than that in consumption. The expansion in output occurs in both the tradable and nontradable production sectors, as a result of a reduction in real wages. The reduction in the devaluation rate lowers inflation and raises the marginal value of wealth, thereby raising the opportunity cost of leisure and inducing an increase in labor supply in the initial phase of the program. The continued reduction in inflation over time leads to further increases in the supply of labor and downward pressure on wages. ${ }^{3}$ However, in neither one of these contributions does the model predict a recession following the expansionary phase, as suggested by some of the evidence.

The purpose of this paper is to explore further the role of supply-side factors in the dynamics of output and absorption in exchange-rate based stabilization programs. ${ }^{4}$ As in some existing studies, such as those of Lahiri (2001) and Roldós (1995), we explicitly model labor supply decisions and capital accumulation in an infinite-horizon, intertemporal optimizing framework with representative agents. The analysis, however, departs from the current literature by assuming (following Agénor $(1997,1998)$ ) that domestic households face imperfect world capital markets. As a result of these imperfections, domestic interest rates are determined by the equilibrium condition of the money market. In optimizing models with infinite horizon and perfect capital mobility (as in most of the contributions cited earlier), it is necessary to impose equality between the (constant) rate of time preference and the world

\footnotetext{
${ }^{3}$ By contrast, Roldós (1995) found that real wages increase during the transition (after falling on impact), whereas the long-run effect of a reduction in the devaliation rate on labor supply is ambiguous.

${ }^{4}$ An analysis of alternative models based on simulation techniques by Rebelo and Végh (1997) emphasized the importance of supply-side factors (notably the role of real wages) in explaining the boom-recession cycle.
} 
interest rate to get a finite and positive level of consumption in the steady state. A problem with that approach, however, is that the steady state - and the adjustment path to it - depends not only on the dynamic structure of the model but also on the economy's initial conditions. ${ }^{5}$ This "hysteresis" phenomenon, as pointed out by Turnovsky and Sen (1991) in a related context, is what results in temporary shocks having permanent effects. ${ }^{6}$ In our framework, by contrast, the rate of time preference does not need to be equal at all times to the world interest rate and there are therefore no hysteresis effects.

More importantly perhaps for the issue at hand, the dynamics of the economy induced by an exchange rate-based disinflation differ dramatically under perfect and imperfect world capital markets, as discussed by Agénor (1997). In the former case, the uncovered-interest-parity condition holds continuously, and private foreign borrowing can take any value a priori. A reduction in the devaluation rate lowers the opportunity cost of holding money and raises the demand for real cash balances, which is matched by an increase in money supply brought about by an instantaneous increase in foreign borrowing. The resulting inflow of capital is monetized by exchanging the foreign exchange for domestic currency at the central bank, in such a way that the economy's net stock of foreign debt remains constant. There are no real effects, and the adjustment process displays no dynamics; the economy jumps instantaneously to the new steady state. By contrast, with imperfect world capital markets, the long-run value of private foreign borrowing is "pinned down" by the difference between the world risk-free interest rate and the rate of time preference, and therefore cannot vary across steady states in response to a change in the devaluation rate. Thus, the increase in real cash balances cannot take place through a once-and-for-all inflow of capital. For

\footnotetext{
${ }^{5}$ Of course, alternative approaches, such as those based on Uzawa preferences or finite lifetimes - as in the Blanchard-Yaari framework used by Helpman and Razin (1987) — could be adopted to alleviate this problem.

${ }^{6}$ Another problem, specific to the Calvo-Végh model, is that the boom-recession cycle in consumption takes the form of step changes - rather than the inverted-U shaped path suggested by the evidence.
} 
official reserves to expand, and for an expansion in money supply to match the increased demand for money, the economy must now generate a sequence of current-account surpluses. In turn, because higher official reserves imply a reduction in the economy's net external debt (given that private foreign borrowing remains constant across steady states), the lower deficit in the services account must be accompanied by a lower trade surplus, that is, higher private consumption. Thus, with imperfect world capital markets, adjustment to a reduction in the devaluation rate generate real effects both during the transition process and the long run. Because we account also for changes in labor supply and capital accumulation in the present paper, we are able to show that these real effects may entail also changes in employment, leisure, and investment.

The remainder of the paper is organized as follows. Section II presents the basic model, which introduces variable labor supply in the framework developed by Agénor $(1997,1998)$, while assuming that the capital stock is constant. Section III examines the short- and long-term effects of a reduction in the nominal devaluation rate in this setting. Section IV extends the basic framework to account for capital accumulation in the presence of installation costs, using a Tobin- $q$ approach to investment decisions. A key feature of the extended model is that, with endogenous labor supply, investment decisions are not independent of consumption decisions. Changes in consumption alter the marginal utility of leisure, and this affects the supply of labor at any given wage. As a result, the marginal product of capital changes and this in turn affects investment - to an extent that depends on capital installment costs. Because of the complexities of the resulting model, the transitional dynamics associated with a reduction in the nominal devaluation rate are examined in Section V using numerical simulations. Finally, Section VI summarizes the main results of the analysis and offers some suggestions for further research. 


\section{The Basic Framework}

As in Agénor (1997), we consider a small open economy in which perfect foresight prevails and four types of agents operate: households, producers, the government, and the central bank. The economy produces a traded good, whose foreign-currency price is constant and normalized to unity. The nominal exchange rate $E$ is depreciated by the central bank at a constant rate, $\varepsilon \equiv \dot{E} / E .^{7}$ The capital stock is fixed initially, and labor is homogeneous. Domestic production takes place under decreasing returns to labor.

\subsection{Households}

Households hold two categories of financial assets in their portfolios: domestic money (which bears no interest) and domestic government bonds (perpetuities). They also borrow on world capital markets, subject to a rising risk premium. Assuming that government expenditure does not yield direct utility, the representative household's discounted lifetime utility is written as

$$
\int_{0}^{\infty}\left[\frac{c^{1-\eta}}{1-\eta}+\ln \lambda^{\alpha} m^{1-\alpha}\right]^{-\rho t} d t
$$

where $\rho>0$ denotes the rate of time preference, $c$ consumption expenditure, $\lambda$ leisure, $m$ real money balances. We also assume that $\eta>0, \eta \neq 1$, and $0<\alpha<1$.

Real wealth of the representative household $a$ is defined as

$$
a=m+b-l^{*}
$$

where $b$ denotes real holdings of government bonds and $l^{*}$ foreign borrowing measured in foreign-currency terms. The flow budget constraint is given by

\footnotetext{
${ }^{7}$ We define $\dot{x} \equiv d x / d t$. In what follows partial derivatives are denoted by corresponding subscripts, while the total derivative of a function of a single argument is denoted by a prime. A sign over a variable refers to the sign of the corresponding partial derivative.
} 


$$
\dot{a}=w n^{s}+\Pi+i b-c-\tau-\left(i^{*}+\theta\right) l^{*}-(m+b) \varepsilon,
$$

where $n^{s}$ denotes labor supply, $w$ the real wage, $\Pi$ firms' profits, $\tau$ lump-sum taxes, $i$ the domestic nominal interest rate. The term $-(m+b) \varepsilon$ accounts for capital losses on real money balances and the stock of domestic bonds resulting from inflation. The effective cost of borrowing faced by the representative household on world capital markets is equal to $i^{*}+\theta$, where $i^{*}$ is the risk-free rate and $\theta$ a risk premium, which is positively related to the household's level of foreign debt:

$$
\theta=\theta\left(l^{*}, \cdot\right), \quad \theta_{l^{*}}>0 .
$$

Thus, domestic households are able to borrow more on world capital markets only at a higher cost. The size of the premium is related positively to the risk of default on loan obligations.

Households treat $w, \Pi, \varepsilon, i, i^{*}$ and $\tau$ as given, internalize the effect of their portfolio decisions on $\theta$, and maximize (1) subject to (3) and (4) by choosing a sequence $\left\{c, m, \lambda, b, l^{*}\right\}_{t=0}^{\infty}$. Let $r=i-\varepsilon$ denote the domestic real rate of interest, and $\sigma=1 / \eta$ the intertemporal elasticity of substitution. Suppose that the household has a fixed time endowment which is normalized to one, so that $n^{s}=1-\lambda$. The first-order optimality conditions are given by:

$$
\begin{gathered}
(1-\alpha) c^{\eta} / m=i, \\
\alpha c^{\eta} /\left(1-n^{s}\right)=w, \\
i=\left(i^{*}+\theta+\varepsilon\right)+l^{*} \theta_{l^{*}}, \\
\dot{c} / c=\sigma(r-\rho),
\end{gathered}
$$

together with the transversality condition $\lim _{t \rightarrow \infty}\left(e^{-\rho t} a\right)=0$. 
Equation (5) equates the marginal rate of substitution between consumption and money to the opportunity cost of holding money, the domestic nominal interest rate. It implies that money demand is related positively to consumption and negatively to the nominal interest rate:

$$
m^{d}=m^{d}(\stackrel{+}{c}, \bar{i}) .
$$

Equation (6) indicates that the marginal rate of substitution between leisure and consumption is equal to the real wage. It yields

$$
n^{s}=n^{s}(\stackrel{+}{w}, \bar{c})
$$

which indicates that labor supply is positively related to the real wage and negatively to consumption.

Equation (7) is the interest rate parity condition that holds under the assumption of imperfect world capital markets. It equates the marginal cost of borrowing abroad and the marginal rate of return on domestic assets. In turn, the marginal cost of foreign borrowing is given by the effective cost of borrowing, $i^{*}+\theta$, plus the devaluation rate and the increase in the cost of servicing the existing stock of foreign loans induced by the marginal increase in the risk premium (itself resulting from the marginal increase in borrowing), $l^{*} \theta_{l^{*}}$.

Equation (7) determines implicitly the private demand for foreign loans. Taking a linear approximation to $\theta$ yields

$$
l^{*}=\left(i-i^{*}-\varepsilon\right) / \gamma
$$

where $\gamma=2 \theta_{l^{*}}>0 .^{8}$

Finally, equation (8) is the familiar Euler equation. The size of the intertemporal elasticity of substitution $\sigma$ determines the extent to which households adjust their consumption profiles in response to changes in the differen-

\footnotetext{
${ }^{8}$ When the premium is independent of the household's level of borrowing (that is, when $\gamma \rightarrow 0$ ), equation (11) yields the uncovered interest parity condition $i=i^{*}+\varepsilon$.
} 
tial between the domestic real interest rate and the rate of time preference. ${ }^{9}$ Because the desired path for labor supply and real money balances depends in part on the desired degree of consumption smoothing, the intertemporal elasticity of substitution plays an important role in determining the overall dynamics of the economy, as discussed later.

\subsection{Firms and the labor market}

The production technology is characterized by decreasing returns to labor:

$$
y=y(n), \quad y^{\prime}>0, y^{\prime \prime}<0,
$$

where the capital stock is taken as given for the moment.

From (12), labor demand is given by $n^{d}=n^{d}(w)$, with $n^{d \prime}=1 / y^{\prime \prime}<0$. The equilibrium condition of the labor market is given by, using (10):

$$
n^{d}(w)=n^{s}(w, c) .
$$

This condition can be solved, under perfect wage flexibility, for the equilibrium wage:

$$
w=w(c), \quad w^{\prime}>0 .
$$

Substituting this result in equation (10) shows that an increase in consumption has both a direct (negative) effect on labor supply as well as an indirect, positive effect. On the one hand, the increase in consumption increases the demand for leisure and directly reduces labor supply. This reduction, on the other, creates excess demand for labor and requires a rise in the market-clearing wage to maintain equilibrium - thereby increasing the supply of labor. It can be verified that the direct effect dominates the indirect effect, so that an increase in consumption unambiguously lowers labor supply. This relationship can be written as

$$
n^{s}=n^{s}[w(c), c]=N(c) . \quad N^{\prime}<0 .
$$

\footnotetext{
${ }^{9}$ Note that without separability in consumption and leisure, the rate of consumption growth would also depend on the rate of real wage growth. This would be the case, for instance, if the instantaneous utility function were to take the form $\left\{c^{\alpha} \lambda^{1-\alpha}\right\}^{1-\eta} /(1-$ $\eta)+\ln m$, with $0<\alpha<1$.
} 
Substituting the market-clearing wage given by (14) in the labor demand equation gives $n^{d}=n^{d}[w(c)]$, which can be substituted in (12) to give

$$
y^{s}=y^{s}(c)
$$

with $y^{s \prime}<0$.

\subsection{Central Bank and the Government}

The central bank devalues the exchange rate at the constant rate $\varepsilon$ and engages in nonsterilized intervention; that is, it ensures the automatic and costless conversion at any given moment in time of domestic currency holdings into foreign currency (and vice versa) at the prevailing exchange rate. Because there is no credit, the real money supply is equal to

$$
m^{s}=R^{*}
$$

where $R^{*}$ is the central bank's stock of net foreign assets, measured in foreigncurrency terms. The central bank receives interest on its holdings of foreign assets, $i^{*} R^{*}$. Capital gains on official foreign reserves, $\varepsilon R^{*}$, normally affect the net worth of the central bank. In what follows we assume that the central bank's net worth remains constant, and that net income -inclusive of capital gains, that is, $\left(i^{*}+\varepsilon\right) R^{*}$ - is transferred to the government.

The government consumes a quantity $g$ of the domestic good, pays interest on its domestic debt, and maintains a balanced budget by levying lump-sum taxes on households. Setting the constant stock of domestic bonds to zero for simplicity, the budget constraint of the government can be written as

$$
\tau=g-\left(i^{*}+\varepsilon\right) R^{*}
$$

Finally, to close the model requires specifying the equilibrium condition

of the money market. From equation (5), the market-clearing interest rate is given by:

$$
i=i(\stackrel{+}{c}, \bar{m}),
$$


which shows that the nominal interest rate depends positively on consumption expenditure and negatively on real money balances.

Appendix A derives the dynamic structure of the model, in terms of a system involving consumption, $c$, and net external debt, $D^{*}=l^{*}-R^{*}$, which is a predetermined variable. Saddlepath stability requires that the $[\dot{c}=0]$ locus be steeper than the $\left[\dot{D}^{*}=0\right]$ locus, as shown in the North-East quadrant of Figure 1. The stable path has a negative slope and is denoted $S S$. In the North-West quadrant, the upward-sloping curve $L L$ traces the combinations of $w$ and $c$ for which the labor market is in equilibrium, as indicated in (14). The South-West quadrant traces the negative relation between wages and the supply of output, obtained by substituting the demand for labor function $n^{d}=n^{d}(w)$ in equation (12). The initial steady-state position of the economy corresponds to points $E, H$, and $Q$ and corresponds to $\dot{c}=\dot{D}^{*}=0$. The real interest rate is equal to the rate of time preference $(\tilde{r}=\tilde{\imath}-\varepsilon=\rho)$, private foreign borrowing is a function of the difference between the rate of time preference and the risk-free rate $\left(\tilde{l}^{*}=\left(\rho-i^{*}\right) / \gamma\right)$, and real money balances are given by $\tilde{m}=m(\tilde{c}, \rho+\varepsilon)$.

\section{Reduction in the Devaluation Rate}

Consider first a permanent and unanticipated reduction in the nominal devaluation rate, $\varepsilon$, with no discrete change in the level of the exchange rate. The reduction in $\varepsilon$ has no long-run effect on the real interest rate (which is tied to the rate of time preference) or private foreign borrowing. But because the nominal interest rate falls in the same proportion as the devaluation rate, thereby reducing the opportunity cost of holding money, the demand for domestic cash balances - at the initial level of consumption - rises. The official stock of reserves must therefore increase to maintain money market equilibrium; and because private foreign borrowing does not change in the long run, the economy's overall stock of debt must fall in the new steady state, implying a lower deficit in the services account. To maintain external balance, 
the initial trade surplus must fall - or equivalently private consumption must rise. The increase in private expenditure also raises the demand for domestic cash balances, lowers the supply of labor, and raises real wages. The fall in employment is associated with a reduction in domestic output - which also helps to reduce the initial trade surplus.

On impact, as shown in Appendix B, the reduction in $\varepsilon$ leads to an increase in private foreign borrowing. This leads in turn to an offsetting increase in official reserves (and thus a rise in the real money stock) to maintain the economy's stock of foreign debt constant. For a given level of consumption, the nominal interest rate falls. For foreign borrowing to increase, the domestic real interest rate must increase; in turn, this implies that the nominal interest rate must fall by less than the reduction in the devaluation rate. The increase in the real interest rate creates an incentive for households to shift consumption toward the future. Consumption therefore falls on impact. As a result of the reduction in private spending, labor supply increases, reducing wages and stimulating output. The trade balance therefore improves. At the same time, the negative income effect associated with the increase in the premium-related component of interest payments (itself resulting from the rise in private foreign borrowing) raises the initial deficit of the services account. Nevertheless, the increase in the trade surplus outweighs the adverse movement in the services account, and the current account improves, leading to a fall in external debt. Because the shock is permanent, the current account remains in surplus throughout the adjustment process.

The dynamics of consumption and net external debt are also illustrated in Figure 1. Both the $[\dot{c}=0]$ and $\left[\dot{D}^{*}=0\right]$ curves shift to the left. Consumption jumps downward from $E$ to $A$ on impact, and begins rising afterward, with the real interest rate falling gradually toward the rate of time preference. The economy's stock of foreign debt falls continuously during the transition to the new steady state, which is reached at $E^{\prime}$. The real wage jumps downward on impact from $H$ to $F$ on the $L L$ curve, and starts rising toward its new long-run equilibrium position, $H^{\prime}$. Output rises on impact from $Q$ to $M$, and 
begins falling afterward (toward $Q^{\prime}$ ), as a result of the gradual increase in wages.

Consider now a temporary reduction for the period $(0, T)$ in the devaluation rate. The adjustment path depends, of course, on the length of the period during which the devaluation rate is reduced. Figure 1 illustrates one particular outcome in which, consumption, after falling from $E$ to $A^{\prime}$, begins to increase. ${ }^{10}$ The current account moves at first into surplus (between $A^{\prime}$ and $B$ ) but turns into deficit; the stock of foreign debt therefore begins to increase. The economy reaches the original saddlepath $S S$ at point $C$, exactly at period $T$. Between $A^{\prime}$ and $C$, consumption and real wages increase, and output falls. After point $C$, consumption and wages start falling and output begins to rise.

Thus, the results associated with a temporary shock indicate that the model is capable of reproducing some of the "stylized facts" of exchangerate based stabilization programs mentioned in the introduction: a boomrecession cycle in output (associated with a reduction and a subsequent increase in real wages) and a current account deficit in the second stage of the adjustment process. Although consumption drops on impact (to an extent that depends on the size of the intertemporal elasticity of substitution), it follows afterward the inverted-U shape pattern observed in some actual programs. Of course, given that the model considers only one good, it cannot reproduce the real exchange rate appreciation that has also characterized some exchange rate-based programs. In addition, the assumption of a constant capital stock in the above framework prevents it from explaining another important feature of exchange rate-based programs, namely, an expansion in investment. To do so requires endogenizing capital accumulation and investment decisions.

\footnotetext{
${ }^{10}$ See Agénor $(1997,1998)$ for a more detailed discussion of the dynamics associated with a temporary reduction in the devaluation rate in a similar model with exogenous labor supply.
} 


\section{Capital Accumulation}

To account for capital accumulation in the framework developed above, we write the production function in the form

$$
y=y(n, k),
$$

where $k$ is the capital stock. The function $y(\cdot)$ is assumed to possess all the standard neoclassical properties. In particular, it exhibits constant returns to scale and production inputs are gross complements $\left(y_{n k}>0\right)$. For simplicity, we also assume that the capital stock does not depreciate over time.

To model investment decisions, we follow the literature on installation costs. In order to invest $I$ units of output, the representative firm must spend $I_{G}=I(1+\Phi)$ units of the good, with $\Phi$ denoting installment costs, which are assumed to depend linearly on the ratio of investment to the existing capital stock, $I / k$ :

$$
I_{G}=I\left(1+\frac{\phi I}{2 k}\right)
$$

with $\phi$ denoting a positive constant that determines the degree of intertemporal substitution in production, that is, the response of investment to a given increase in the shadow value of capital. ${ }^{11}$

Using (21), the firm's cash flow is thus given by

$$
y(n, k)-w n-I\left(1+\frac{\phi I}{2 k}\right),
$$

which is linearly homogeneous in capital, labor and investment.

Suppose now that the representative firm maximizes the net present value of its future earnings, given its production technology and capital stock, which evolves over time according to

$$
\dot{k}=I \text {. }
$$

\footnotetext{
${ }^{11}$ See Abel and Bnlanchard (1983) and, more recently, Servén (1996). Convex adjustment costs give firms an incentive to smooth the adjustment path of the stock of capital over a period of time, with the optimal amount of adjustment depending on the differential between the equity price of capital over the unitary replacement cost. By contrast, nonconvexities in the adjustment cost function would tend to cause discontinuous adjustment in the capital stock.
} 
The firm's optimal behavior can thus be described as

$$
V=\max _{I, n} \int_{t}^{\infty}\left\{y(n, k)-w n-I\left(1+\frac{\phi I}{2 k}\right)\right\} e^{-\rho t} d t
$$

given $k .^{12}$ The optimality conditions are given by

$$
\begin{gathered}
y_{n}(n, k)=w, \Rightarrow n^{d}=n^{d}(\bar{w}, \stackrel{+}{k}), \\
I=\frac{k}{\phi}(q-1), \\
q=\int_{t}^{\infty}\left\{y_{k}(n, k)-\frac{\phi}{2}\left(\frac{I}{k}\right)^{2}\right\} e^{-\rho(t-s)} d s,
\end{gathered}
$$

together with the transversality condition $\lim _{t \rightarrow \infty}\left(e^{-\rho t} k\right)=0$.

Equation (24) is the demand for labor, derived by equating the marginal productivity of labor $y_{n}(n, k)$ to the going wage, $w$. Equation (25) determines the desired level of investment, where $q$ is the ratio of the value of installed capital to its replacement cost - that is, Tobin's $q$, which, as shown in (26), is such that the shadow value of capital equals the present value of its marginal product. ${ }^{13}$ As shown by Hayashi (1982), under the assumptions of a constantreturns-to-scale technology and homogeneity of degree one of installation costs (as is the case here), the marginal value of installed capital is equal to the average value of installed capital. Put differently, $q$ can also be interpreted as the market value of an equity claim on a unit of installed capital.

Equation (26) yields

$$
\dot{q}=\rho q-y_{k}(n, k)+\frac{\phi}{2}\left(\frac{I}{k}\right)^{2},
$$

\footnotetext{
${ }^{12}$ For simplicity, the firm's discount factor is assumed to be same as the one used by the representative household.

${ }^{13}$ Equation (25) can be rewritten as $q=1+\phi I / k$, where the right-hand side term is the marginal increase in gross investment resulting from a marginal increase in net investment. Thus, the optimal investment rate is determined by setting the marginal benefit equal to the marginal investment cost.
} 
where the last two terms represent the difference between the marginal cost of adding new capacity and the marginal product of capital. ${ }^{14}$

Households behave as specified before. In particular, labor supply is again given by equation (10). However, the representative household's real wealth (equation (2)) is now given by

$$
a=m+b+q k-l^{*}
$$

In addition, because labor demand depends now on the capital stock, the equilibrium wage rate obtained by solving (13) is now also a function of the capital stock, in addition to consumption:

$$
w=w(\stackrel{+}{c}, \stackrel{+}{k})
$$

Substituting equation (29) in (24) and using (20) yields ${ }^{15}$

$$
y^{s}=y^{s}(\bar{c}, \stackrel{+}{k}), \quad y_{k}(n, k)=h(\bar{c}, \bar{k}) .
$$

Using (25) and (30), equation (27) can be written as

$$
\dot{q}=\rho q-h(c, k)+\frac{(q-1)^{2}}{2 \phi}
$$

Substituting (25) in (21) yields gross investment as

$$
I_{G}=\frac{k}{\phi}(q-1)\left(1+\frac{q-1}{2}\right) \equiv k v(q),
$$

with $v^{\prime}>0$ and $v(1)=0$. The dynamics of the capital stock are governed by, from (23) and (25):

$$
\dot{k}=\frac{k}{\phi}(q-1) .
$$

\footnotetext{
${ }^{14}$ Note that, from (25), if $\phi=0$, investment takes place instantaneously, $q$ will always be equal to unity and the capital stock will be constant. At any point in time, the value of the capital stock will equal its replacement cost. The reason, of course, is that it makes sense to have less than full adjustment of the capital stock only when adjustment entails some cost.

${ }^{15}$ In signing $h_{k}$, it is assumed that the direct effect of an increase in $k$ on the marginal product of capital outweighs its indirect effect on the marginal productivity of labor.
} 
With the same assumptions as before regarding the government and the central bank, and using (28), (30), and (32), the consolidated flow budget constraint of the economy is given by

$$
\dot{D}^{*}=i^{*} D^{*}+\theta l^{*}+c+g+k v(q)-y^{s}(c, k) .
$$

The dynamic model now consists of (8), (11), (31), (33) and (34). By eliminating $l^{*}$ (as in Appendix A), this set of equations can be further condensed into a differential equation system involving four variables: private consumption $c$, Tobin's $q$, the economy's net stock of external debt, $D^{*}$, and the capital stock, $k$. The system possesses two jump variables, $c$ and $q$, whereas $k$ and $D^{*}$ are predetermined variables. Saddlepath stability therefore requires two positive and two negative roots. Appendix C discusses the conditions under which this is indeed the case.

The steady-state values of the system are given by

$$
\begin{gathered}
\tilde{r}=\tilde{\imath}-\varepsilon=\rho . \\
\tilde{l}^{*}=\left(\rho-i^{*}\right) / \gamma, \\
\tilde{m}=m(\tilde{c}, \rho+\varepsilon), \\
\tilde{q}=1, \\
h(\tilde{c}, \tilde{k})=\rho \Rightarrow \tilde{k}=s(\tilde{c}),
\end{gathered}
$$

with $s^{\prime}<0$, and

$$
\tilde{c}=y^{s}(\tilde{c}, \tilde{k})-g-i^{*} \tilde{D}^{*}-\tilde{\theta} \tilde{l}^{*},
$$

because $\tilde{I}_{G}=0$. Conditions (35), (36), and (37) are similar to those given earlier in the absence of capital accumulation.

As shown also in Appendix C, the steady-state effects of a reduction in the devaluation rate are qualitatively similar to those obtained in the model 
without capital accumulation (see Appendix B). This is intuitively clear from (38) and (39) which show that $q$ is invariant to any shock, and the capital stock varies inversely with consumption; as a result, solving for the steadystate effect involves solving simultaneously only for $c$ and $D^{*}$. In the long run, therefore, a permanent reduction in the devaluation is associated with a lower capital stock and lower output. But given the complexity of the model, it is not possible to analyze explicitly its transitional dynamics in response to any given shock. As a result, we use numerical simulations to study the adjustment process associated with an exchange-rate based stabilization.

\section{Numerical Simulations}

To analyze numerically the effects of a reduction in the devaluation rate in our nonlinear, forward-looking model, we used Portable TROLL. The solution procedure that we use is based on a Newton stacked-time algorithm. It involves stacking the time-dependent equations of the model such that each endogenous variable is represented by an independent equation. The stacked structure is then solved simultaneously using a Newton procedure. ${ }^{16}$ The effects of both permanent and temporary reductions in the devaluation rate are evaluated using two alternative values of the intertemporal elasticity of substitution, $\sigma$.

The numerical values assigned to the variables and parameters of the system dwell on the existing empirical literature and are given as follows. The initial devaluation (or inflation) rate is set at 3 percent, and both a permanent and a temporary drop by one percentage point in this rate are considered. On the supply side of the model, output $y$ is normalized to 1000; the production function is assumed to have a constant elasticity of substitution between labor and capital equal to 0.56 . This value is relatively high but it is consistent with the evidence on the degree of substitution between physical capital and unskilled labor (see for instance Roberts and

\footnotetext{
${ }^{16}$ See for instance Armstrong, Black, Laxton, and Rose (1998) for a discussion of this procedure.
} 
Skoufias (1997)). The real interest rate, $r$, is initially set to 4 percent, the same value as the rate of time preference, $\rho$. Consumption, $c$, is calibrated to have an initial value equal to 80 percent of total output $(c=800)$, whereas the intertemporal elasticity of substitution, $\sigma$, takes the values of 0.3 and 0.8 for the two scenarios under consideration. ${ }^{17}$ These values are consistent with the range of empirical estimates reviewed by Agénor and Montiel (1999). Net external debt, $D$, is set at an initial value of 700 , with private external liabilities, $l^{*}$, taking the value of 1000 ; these values imply therefore that $R^{*}=m=1000-700=300$. The risk premium, $\theta$, is assumed to take the quadratic (convex) form $\gamma l^{* 2} / 2$. Finally, the parameter $\phi$, which represents the installation cost of investment, is set at 0.1 .

Calibration of the model around these initial values produces the baserun solution. For the permanent disinflation shock, the initial value of the devaluation rate is reduced permanently by 1 percentage point for all 100 periods considered in this simulation, with each period corresponding to a quarter. For the temporary shock, the devaluation rate is reduced by 1 percentage point only for the first ten periods (that is, 2.5 years), and then returns to its initial value of 3 percent. The effect of these shocks on output, consumption, labor supply, net investment, the real interest rate, the current account balance, external debt, and the capital stock are reported in Figures 2 and 3. In both cases, the key variable that drives the short-run dynamics is the real interest rate (which increases on impact) because of its effect on intertemporal decisions.

Consider first a permanent reduction in the devaluation rate. As shown in Figure 2, consumption, labor supply, wages, output, and the real interest rate behave in a manner similar to what we obtained in the basic model without capital accumulation. The reason is that the main mechanism behind

\footnotetext{
${ }^{17}$ For the numerical simulations, the instantaneous utility function appearing in equation (1) was modified to $c^{1-\eta} /(1-\eta)+\ln \lambda^{\mu} m^{\alpha}$, in order to distinguish between labor supply and money demand elasticities. Consequently, the money demand function is derived from the condition $i=\alpha c^{\eta} / m$ and the labor supply function from $n^{s}=1-\mu c^{\eta} / w$, where $\lambda=1-n^{s}$ and the time endowment is set equal to unity.
} 
these dynamics is not altered as by introducing investment. The drop in the devaluation rate leads to an initial increase in private foreign borrowing, which leads to an increase in official reserves (and consequently a rise in the real money stock), because foreign debt remains constant on impact. In turn, this leads to a fall in the nominal interest rate, but by an amount smaller than the fall in the devaluation rate -implying that the real interest rate unambiguously rises on impact. As a result, households have an incentive to shift consumption toward the future. The fall in initial consumption increases labor supply, which lowers the real wage rate and boosts production. The long-run equilibrium is also in line with the steady-state results of the basic model - in particular, higher consumption and lower output.

The introduction of capital accumulation, however, does alter the effects on the current account and external debt. The behavior of investment subsequent to a devaluation shock is in line with the evidence with the boomrecession cycle. As labor supply and output rise, so does investment due to its complementarity to labor in the production process. Because in the extended model investment enters the external debt equation (see Equation (34)), the overall effect on the current account is ambiguous and depends on the values of parameters. With a low level of intertemporal elasticity of substitution in consumption (as suggested by much of the empirical evidence reviewed by Agénor and Montiel (1999)), the initial drop in consumption is relatively small (compare in Figure 2 the results for the different values of $\sigma)$. Instead, given relatively low installation costs, investment experiences a more pronounced boom that outweighs consumption in shaping the behavior of domestic absorption, which therefore follows a boom-recession pattern. Depending on the parameters used (in Figure 2 only $\sigma$ varies), domestic absorption may outweigh the effects of output on the trade deficit, thereby leading to a current account deficit. As expected, these results depend very much on the size of the intertemporal elasticity of substitution.

Figure 3 shows the effects of a temporary reduction in the devaluation rate for ten periods only. As could be expected from the foregoing discussion, the 
results obtained for the first phase of the adjustment process are qualitatively similar to those obtained with a permanent shock. A key difference in the present case is that the real interest rate experiences a discrete drop once the shock is removed, that is, at period 10. On impact, and during the first few periods of the adjustment process, all variables behave in a way similar to what is obtained with the permanent shock. Over time, all variables now return to their initial baserun values, including the level of external debt and the stock of capital. In particular, the initial sequence of current account surpluses is followed by a sequence of current account deficits.

In interpreting movements in the current account balance in this model, it is important to keep in mind that we have assumed the elasticity of substitution between labor and capital to be relatively high (0.56). With lower values of that elasticity, the model could generate trade and current account deficits on impact with a temporary shock, and possibly with a permanent shock as well; the reason is that with now two negative roots, adjustment even with a permanent shock does not need to be monotonic. ${ }^{18}$ With a temporary shock, and even with the current value of the elasticity of substitution between capital and labor, it is also possible to generate external deficits on impact depending on the length of the period during which the shock is maintained - very much like in the experiment described in Figure 1 .

Thus, numerical simulations of a temporary reduction in the devaluation rate appear to replicate fairly well the boom-recession cycle in output and domestic absorption associated with the type of exchange rate-based stabilization programs often implemented in developing countries. Although consumption, once again, displays a small downward jump on impact, it does follow afterward an inverted-U pattern, as suggested by the evidence. ${ }^{19}$

\footnotetext{
${ }^{18}$ In the model without capital accumulation, a permanent shock can induce only monotonic movements in the stock of external debt because of the existence of only one negative root.

${ }^{19}$ Note that the drop in consumption occurs despite the fact that output rises on impact. This is in part due to the way leisure is modeled in the utility function - that is, the assumption that utility is homogeneous of degree one in leisure and money balances,
} 
And if the impact response of investment is sufficiently strong, domestic absorption would always increase on impact. The key assumptions needed to obtain these results are a low value of the intertemporal elasticity of substitution in consumption (as observed in empirical studies) and low investment installation costs.

\section{Summary and Conclusions}

This paper studied the role of supply-side factors in the dynamics of output and domestic absorption in exchange-rate based stabilization programs. First, a basic framework was presented to illustrate the main differences between this study and some of the existing analytical literature on these programs. In particular, the economy was modeled using an infinite-horizon, intertemporal optimizing framework in which labor supply is endogenous and domestic households face imperfect world capital markets. With imperfect capital mobility, equality between the rate of time preference does not need to be equal at all times to the world interest rate to ensure a stationary solution (which therefore does not depend on initial values), and a permanent reduction in the devaluation rate entails transitional dynamics. It was shown that a temporary reduction in the devaluation rate leads to a boom-recession cycle in output and consumption (in the latter case following an initial, short-lived downward movement) and a sequence of current account deficits, all in line with some of the evidence on exchange-rate based stabilization. The basic framework was then further extended to account for capital accumulation in the presence of investment installation costs. We showed that the extended model was able to replicate a boom-recession behavior for investment and domestic absorption as well, as suggested by the evidence. This behavior emerges from both permanent and transitory shocks.

and additively separable in consumption. A more general specification would lead to consumption rising on impact, as a result of a wealth effect. However, our aim here is not to consider such effects, and therefore chose a specification of the utility function that precludes them. 
The major economic variable that our analysis of exchange-rate based stabilization fails to describe is the real exchange rate. This limitation is due, of course, to the fact that we model a one-good economy only. However, our framework can be further developed to include traded and nontraded sectors, as in some existing contributions, as well as distribution costs, which appear to be important to explain the existing evidence (see Burstein, Neves, and Rebelo (2003)). With sticky prices in the nontradables sector, for instance, a reduction of the devaluation rate would directly affect prices in the traded sector only, implying that overall inflation would not fall by as much as the devaluation rate. This would lead to an appreciation of the real exchange rate, as documented in the evidence. The distinction between tradables and nontradables would provide further insight on the behavior of consumption and the current account, notably by allowing for intratemporal substitution, in addition to consumption smoothing considerations. 


\section{References}

Abel, Andrew B., and Olivier J. Blanchard, "An Intertemporal Model of Saving and Investment," Econometrica, 51 (May 1983), 675-92.

Agénor, Pierre-Richard, Capital-Market Imperfections and the Macroeconomic Dynamics of Small Indebted Economies, Princeton Study in International Finance No. 82 (June 1997).

_ _ "The Behavior of Real Interest Rates in Exchange-Rate Based Stabilization Programs," Review of Development Economics, 2 (October 1998), 231-49.

Agénor, Pierre-Richard, and Peter J. Montiel, Development Macroeconomics, 2nd ed., Princeton University Press (Princeton, New Jersey: 1999).

Armstrong, J., R. Black, Douglas Laxton, and D. Rose, "A Robust Method for Simulating Forward-Looking Models," Journal of Economic Dynamics and Control, 22 (April 1998), 489-501.

Burstein, Ariel T., Joao C. Neves, and Sergio Rebelo, "Distribution Costs and Real Exchange Rate Dynamics during Exchange-Rate-Based Stabilizations," Journal of Monetary Economics, 50 (September 2003), 1189-214.

Calvo, Guillermo A., and Carlos A. Végh, "Exchange Rate-Based Stabilization under Imperfect Credibility," in Open Economy Macroeconomics, ed. by Helmut Frisch and Andreas Worgotter, St. Martin's Press (New York: 1993).

_ , "Inflation Stabilization and Nominal Anchors," Contemporary Economic Policy, 12 (April 1994), 35-45.

De Gregorio, José, Pablo E. Guidotti, and Carlos A. Végh, "Inflation Stabilization and the Consumption of Durable Goods," Economic Journal, 108 (January 1998), 105-31.

Easterly, William, "When is Stabilization Expansionary? Evidence from High Inflation," Economic Policy, No. 22 (April 1996), 65-98.

Fischer, Stanley, Ratna Sahay, and Carlos A. Végh, "Moder Hyper- and High Inflations," Journal of Economic Literature, 40 (September 2002), 837-80.

Gould, David M., "Does the Choice of Nominal Anchor Matter?," Working Paper No. 96-11, Federal Reserve Bank of Dallas (October 1996). 
Hamann, A. Javier, "Exchange-Rate-Based Stabilization: A Critical Look at the Stylized Facts," IMF Staff Papers, 48 (March 2001), 111-38.

Hayashi, Fumio, "Tobin's Marginal $q$ and Average $q$ : A Neoclassical Interpretation," Econometrica, 50 (January 1982), 213-24.

Helpman, Elhanan, and Assaf Razin, "Exchange Rate Management: Intertemporal Tradeoffs," American Economic Review, 77 (March 1987), 107-23.

Lahiri, Amartya, "Exchange Rate Based Stabilizations under Real Frictions: The Role of Endogenous Labor Supply," Journal of Economic Dynamics and Control, 25 (August 2001), 1157-77.

Obstfeld, Maurice, "The Capital Inflows Problem Revisited: A Stylized Model of Southern Cone Disinflation," Review of Economic Studies, 52 (October 1985), 605-25.

Reinhart, Carmen M., and Carlos A. Végh "Nominal Interest Rates, Consumption Booms, and Lack of Credibility: A Quantitative Examination," Journal of Development Economics, 46 (April 1995), 357-78.

Roberts, Mark J., and Emmanuel Skoufias, "The Long-Run Demand for Skilled and Unskilled Labor in Colombian Manufacturing Plants," Review of Economics and Statistics, 79 (May 1997), 330-34.

Roldós, Jorge, "Supply-Side Effects of Disinflation Programs," IMF Staff Papers, 42 (March 1995), 158-83.

— , "On Gradual Disinflation, the Real Exchange Rate, and the Current Account," Journal of International Money and Finance, 16 (February 1997), $37-54$.

Servén, Luis, "Capital Goods Imports, the Real Exchange Rate and the Current Account," Journal of International Economics, 39 (August 1995), 79-101.

Stockman, Alan, "Anticipated Inflation and the Capital Stock in a Cash-inAdvance Economy," Journal of Monetary Economics, 8 (June 1981), 387-96. Turnovsky, Stephen J., and Partha Sen, "Fiscal Policy, Capital Accumulation, and Debt in an Open Economy," Oxford Economic Papers, 43 (January 1991), 1-24.

Uribe, Martín, "Exchange-Rate-Based Inflation Stabilization: The Initial Real 
Effects of Credible Plans," Journal of Monetary Economics, 39 (July 1997), 197-221.

Végh, Carlos A., "Stopping High Inflation: an Analytical Overview," IMF Staff Papers, 39 (September 1992), 626-95.

Rebelo, Sergio, "What Happens when Countries Peg their Exchange Rates?," Discussion Paper No. 1692, Centre for Economic Policy Research (August 1997).

Rebelo, Sergio, and Carlos A. Végh, "Real Effects of Exchange-Rate Based Stabilization: An Analysis of Competing Theories," NBER Macroeconomics Annual 1996, ed. by Ben S. Bernanke and Julio J. Rotemberg, MIT Press (Cambridge, Mass.: 1997). 


\section{Appendix A \\ Basic Framework: Dynamic Form}

Substituting (17) in (2) yields, given the normalization rule for $b$ :

$$
D^{*}=-a=l^{*}-R^{*},
$$

which shows that, since the net worth of the central bank and the government does not change over time (given the tansfer rule and a continuously balanced budget), the private sector's net financial liabilities consist of the economy's net stock of foreign debt (measured in foreign-currency terms), $D^{*}$, which is defined as the difference between private foreign liabilities and official foreign assets.

Substituting equations (18) and (A1) in (3) yields the consolidated budget constraint of the economy:

$$
\dot{D}^{*}=i^{*} D+\theta l^{*}+c+g-y^{s},
$$

which indicates that the current account deficit (whose counterpart is the change in foreign debt) is the sum of the trade deficit and interest payments on the outstanding stock of debt held by households and the central bank. ${ }^{20}$

Equations (8), (11), (16), (17), (19) and (A2) describe the evolution of the economy along any perfect foresight equilibrium path. The system can be re-written as:

$$
l^{*}=\left[i\left(c, R^{*}\right)-i^{*}-\varepsilon\right] / \gamma,
$$

\footnotetext{
${ }^{20}$ Integrating equation (A2) yields the economy's intertemporal budget constraint

$$
D_{0}^{*}=\int_{0}^{\infty}\left(y^{s}-c-g-\theta l^{*}\right) e^{-\int_{0}^{t} i_{h}^{*} d h} d t+\lim _{t \rightarrow \infty} D^{*} e^{-\int_{0}^{t} i_{h}^{*} d h} .
$$

The economy cannot maintain indefinitely a positive or negative net debtor position with the rest of the world, so the second term on the right-hand side in the above expression must be zero. Thus, the current level of foreign debt must be equal to the discounted stream of the excess of future production over domestic absorption plus premium-related interest payments on private foreign borrowing.
} 


$$
\begin{gathered}
\dot{c} / c=\sigma\left[i\left(c, R^{*}\right)-\varepsilon-\rho\right], \\
\dot{D}^{*}=i^{*} D+\theta l^{*}+c+g-y^{s}(c),
\end{gathered}
$$

with equation (18) determining residually lump-sum taxes.

The dynamic form of the model can be further reduced to a system involving two variables: consumption $c$, which may jump in response to new information, and net external debt $D^{*}$, which is a predetermined variable that can change only over time through current account deficits and surpluses. To begin with, note that

$$
R^{*}=-\left(l^{*}-R^{*}\right)+l^{*}=-D^{*}+l^{*},
$$

or, using equation (A3):

$$
R^{*}=-D^{*}+\left[i\left(c, R^{*}\right)-i^{*}-\varepsilon\right] / \gamma,
$$

so that

$$
R^{*}=\varphi\left(\stackrel{+}{c}, \bar{D}^{*} ; \bar{\varepsilon}\right),
$$

where, setting $\beta \equiv 1 /\left(\gamma-i_{m}\right)>0$ :

$$
\varphi_{c}=\beta i_{c}, \quad \varphi_{D}=-\beta \gamma, \quad \varphi_{\varepsilon}=-\beta .
$$

Substituting this result in equation (A4) yields

$$
\dot{c} / c=\sigma\left\{i\left[c, \varphi\left(c, D^{*}, \varepsilon\right)\right]-\varepsilon-\rho\right\},
$$

so that

$$
\dot{c}=G\left(\stackrel{+}{c}, \stackrel{+}{D^{*}} ; \bar{\varepsilon}\right)
$$

where, with $\Delta=\sigma \tilde{c} \gamma \beta$ : 


$$
G_{c}=i_{c} \Delta, \quad G_{D^{*}}=-i_{m} \Delta, \quad G_{\varepsilon}=-\Delta .
$$

Substituting equation (A6) into (A3) yields

$$
l^{*}=\Lambda\left(\stackrel{+}{c}, \stackrel{+}{D^{*}} ; \bar{\varepsilon}\right)
$$

where

$$
\Lambda_{c}=i_{c} \beta, \quad \Lambda_{D^{*}}=-i_{m} \beta, \quad \Lambda_{\varepsilon}=-\beta .
$$

Using (A8), equation (A5) can be written as

$$
\dot{D}^{*}=i^{*} D^{*}+\theta\left[\Lambda\left(c, D^{*}, \varepsilon\right)\right] \Lambda\left(c, D^{*}, \varepsilon\right)+c+g-y^{s}(c),
$$

which can be rewritten as

$$
\dot{D}^{*}=\Psi\left(\stackrel{+}{c}, \stackrel{+}{D^{*}} ; \bar{\varepsilon}\right),
$$

where, with a ' ' denoting initial steady-state values:

$\Psi_{c}=1-y^{s \prime}+\left(\tilde{\theta}+\tilde{l}^{*} \theta_{l^{*}}\right) \Lambda_{c}, \quad \Psi_{D^{*}}=i^{*}+\left(\tilde{\theta}+\tilde{l}^{*} \theta_{l^{*}}\right) \Lambda_{D^{*}}, \quad \Psi_{\varepsilon}=\left(\tilde{\theta}+\tilde{l}^{*} \theta_{l^{*}}\right) \Lambda_{\varepsilon}$

Equations (A7) and (A9) form a dynamic system in consumption and net external debt, which can be linearized around the steady state to give

$$
\left[\begin{array}{c}
\dot{c} \\
\dot{D}^{*}
\end{array}\right]=\left[\begin{array}{ll}
G_{c} & G_{D^{*}} \\
\Psi_{c} & \Psi_{D^{*}}
\end{array}\right]\left[\begin{array}{c}
c-\tilde{c} \\
D^{*}-\tilde{D}^{*}
\end{array}\right]
$$

Since $c$ is a jump variable whereas $D^{*}$ is predetermined - evolving continuously from its initial level $D_{0}^{*}$ - saddlepath stability requires one unstable (positive) root. $^{21}$ To ensure that this condition holds, the determinant of the matrix of coefficients in (A10) - which is equal to the product of the

\footnotetext{
${ }^{21}$ Note that although the overall net stock of external debt $D^{*}$ cannot change on impact, both official reserves and private foreign borrowing may shift discretely in response to changes in interest rates because intervention is unsterilized.
} 
roots - must be negative: $\Psi_{D^{*}} G_{c}-\Psi_{c} G_{D^{*}}<0$. This condition is interpreted graphically in Figure 1.

The steady-state solution is obtained by setting $\dot{c}=\dot{D}^{*}=0$. From equation (A4), the real interest rate is equal to the rate of time preference:

$$
\tilde{r}=\tilde{\imath}-\varepsilon=\rho .
$$

Substituting this result in (A3) yields

$$
\tilde{l}^{*}=\left(\rho-i^{*}\right) / \gamma
$$

which indicates that the steady-state level of private foreign debt is positive as long as the rate of time preference of domestic consumers is sufficiently high - that is, if domestic households value the future sufficiently. ${ }^{22}$

In the long-run the current account must be in equilibrium, so that, from (A5):

$$
\tilde{c}=\tilde{y}^{s}-g-i^{*} \tilde{D}^{*}-\tilde{\theta} \tilde{l}^{*} .
$$

Finally, from (9) and (A11), long-run real money balances are given by

$$
\tilde{m}=m(\tilde{c}, \rho+\varepsilon) .
$$

The steady-state equilibrium of the model is depicted in Figure 1. In the North-East quadrant, the locus $\left[\dot{D}^{*}=0\right]$ gives the combinations of $c$ and $D^{*}$ for which net private financial liabilities (or, equivalently here, the economy's net stock of foreign debt) remain constant, whereas the locus $[\dot{c}=0]$ depicts the combinations of $c$ and $D^{*}$ for which consumption does not change over time. Since $\Psi_{D^{*}}>0, \dot{D}^{*}$ is positive (negative) when $D^{*}$ is to the right (left) of the $\left[\dot{D}^{*}=0\right]$ locus. The positive sign of $G_{D}$ also implies that $\dot{c}$ is positive to the right of the $[\dot{c}=0]$ locus and negative to the left of it. This explains the directions of the arrows.

Saddlepath stability requires that the $[\dot{c}=0]$ locus be steeper than the $\left[\dot{D}^{*}=0\right]$ locus. The stable path has a negative slope and is denoted $S S$.

\footnotetext{
${ }^{22}$ This equation can also be written as $i^{*}+\gamma \tilde{l}^{*}=\rho$, which indicates the consumers must equate the marginal cost of borrowing to their rate of time preference.
} 


\section{Appendix B \\ Basic Framework: \\ Impact and Steady-State Effects \\ of a Reduction in the Devaluation Rate}

The saddlepath solution to the system is given by

$$
c-\tilde{c}=\kappa\left(D^{*}-\tilde{D}^{*}\right),
$$

where $\kappa \equiv\left(\nu-\Psi_{D^{*}}\right) / \Psi_{c}=G_{D^{*}} /\left(\nu-G_{c}\right)<0$ and $\nu$ denotes the negative root of the system.

It can be established that

$$
\begin{gathered}
d \tilde{c} / d \varepsilon=\left(\Psi_{\varepsilon} G_{D^{*}}-\Psi_{D^{*}} G_{\varepsilon}\right) / \Omega<0, \\
d \tilde{D}^{*} / d \varepsilon=\left(\Psi_{c} G_{\varepsilon}-\Psi_{\varepsilon} G_{c}\right) / \Omega
\end{gathered}
$$

where, as shown in the text, $G_{\varepsilon}, \Psi_{\varepsilon}<0$ and (for stability) $\Omega=\Psi_{D^{*}} G_{c}-$ $\Psi_{c} G_{D^{*}}<0$. To show that $d \tilde{c} / d \varepsilon<0$ requires showing that $\Psi_{\varepsilon} G_{D^{*}}-\Psi_{D^{*}} G_{\varepsilon}>$ 0 or that

$$
\Psi_{\varepsilon} / \Psi_{D^{*}}>G_{\varepsilon} / G_{D^{*}}=\left(i_{m} \varphi_{\varepsilon}-1\right) / i_{m} \varphi_{D^{*}}=1 / i_{m},
$$

or equivalently

$$
\left(\tilde{\theta}+\tilde{l}^{*} \theta_{l^{*}}\right) \Lambda_{\varepsilon}>i_{m}^{-1}\left[i^{*}+\left(\tilde{\theta}+\tilde{l}^{*} \theta_{l^{*}}\right) \Lambda_{D^{*}}\right]
$$

Again, with $\Lambda_{D^{*}}=-i_{m} \beta$ and $\Lambda_{\varepsilon}=-\beta$ :

$$
-\beta\left(\tilde{\theta}+\tilde{l}^{*} \theta_{l^{*}}\right)>i_{m}^{-1}\left[i^{*}-i_{m} \beta\left(\tilde{\theta}+\tilde{l}^{*} \theta_{l^{*}}\right)\right],
$$

or $i^{*} / i_{m}<0$, which always holds because $i_{m}<0$. From the steady-state condition $(\mathrm{A} 11), d \tilde{\imath} / d \varepsilon=1$. From (A14):

$$
d \tilde{m} / d \varepsilon=m_{c} d \tilde{c} / d \varepsilon+m_{i}<0
$$


which implies that $d \tilde{R}^{*} / d \varepsilon=d \tilde{m} / d \varepsilon<0$. This, in turn, implies that, because $d \tilde{l}^{*} / d \varepsilon=0$ :

$$
d \tilde{D}^{*} / d \varepsilon=-d \tilde{R}^{*} / d \varepsilon>0 .
$$

On impact, using (B1) and (B2) and noting that $d D_{0}^{*} / d \varepsilon=0$ and $G_{D^{*}}+$ $\kappa G_{c}=\kappa \nu$ :

$$
d c_{0} / d \varepsilon=d \tilde{c} / d \varepsilon-\kappa\left(d \tilde{D}^{*} / d \varepsilon\right)=-\nu\left(G_{\varepsilon}-\kappa \Psi_{\varepsilon}\right) / \Omega>0 .
$$

From the equilibrium condition of the money market

$$
d i_{0} / d \varepsilon=\left(i_{c}+i_{m} \varphi_{c}\right)\left(d c_{0} / d \varepsilon\right)+i_{m} \varphi_{\varepsilon}>0
$$

Since $i_{c}+i_{m} \varphi_{c}$ and $i_{m} \varphi_{\varepsilon}$ are both positive. It can be established that $d i_{0} / d \varepsilon \rightarrow 1$ when $\gamma \rightarrow 0$, and that $d i_{0} / d \varepsilon<1$ for $\gamma>0$.

Finally, from equation (A3), and given that $d i_{0} / d \varepsilon<1$ :

$$
d l_{0}^{*} / d \varepsilon=\gamma^{-1}\left\{\left(d i_{0} / d \varepsilon\right)-1\right\}<0 .
$$

Because $d D_{0}^{*} / d \varepsilon=0$,

$$
d R_{0}^{*} / d \varepsilon=d m_{0} / d \varepsilon=d l_{0}^{*} / d \varepsilon<0 .
$$




\section{Appendix C \\ Extended Framework: \\ Stability Conditions and Steady-State Effects}

Using the solution for $l^{*}$ derived in Appendix A, the current account equation (34) can be written as

$$
\dot{D}^{*}=i^{*} D^{*}+\theta\left[\Lambda\left(c, D^{*}, \varepsilon\right)\right] \Lambda\left(c, D^{*}, \varepsilon\right)+c+g+k v(q)-y^{s}(c, k),
$$

that is

$$
\dot{D}^{*}=\Psi\left(\stackrel{+}{c}, \stackrel{+}{D^{*}}, \stackrel{+}{q}, \bar{k} ; \bar{\varepsilon}\right),
$$

with $\Psi_{D^{*}}$ and $\Psi_{\varepsilon}$ as defined in the text and now (noting that $v(1)=0$ ):

$$
\Psi_{c}=1-y_{c}^{s}+\left(\tilde{\theta}+\tilde{l}^{*} \theta_{l^{*}}\right) \Lambda_{c}, \quad \Psi_{q}=\tilde{k} v^{\prime}, \quad \Psi_{k}=-y_{k}^{s},
$$

The dynamic system now consists of (A7), (31), (33), and (C1). Taking a linear approximation around the initial steady state yields

$$
\left[\begin{array}{l}
\dot{c} \\
\dot{q} \\
\dot{D}^{*} \\
\dot{k}
\end{array}\right]=\left[\begin{array}{llll}
G_{c} & 0 & G_{D^{*}} & 0 \\
-h_{c} & \rho & 0 & -h_{k} \\
\Psi_{c} & \Psi_{q} & \Psi_{D^{*}} & \Psi_{k} \\
0 & \tilde{k} / \phi & 0 & 0
\end{array}\right]\left[\begin{array}{c}
c-\tilde{c} \\
q-1 \\
D^{*}-\tilde{D}^{*} \\
k-\tilde{k}
\end{array}\right] .
$$

Let $\mathbf{A}$ denote the matrix of coefficients on the right-hand side of $(\mathrm{C} 2)$. We have

$$
\begin{gathered}
\operatorname{tr} \mathbf{A}=\mathbf{G}_{c}+\rho+\Psi_{D^{*}}>0, \\
\operatorname{det} \mathbf{A}=\frac{\tilde{k}}{\phi}\left[h_{c} G_{D *} \Psi_{k}+h_{k}\left(G_{c} \Psi_{D^{*}}-\Psi_{c} G_{D *}\right)\right]>0,
\end{gathered}
$$

where in (C4) it is assumed that the condition $G_{c} \Psi_{D *}-\Psi_{c} G_{D *}<0$, which was shown to be necessary for saddlepath stability in the basic model, holds (see Appendix A). Result (C3) implies that there is at least one positive root. Given (C3), (C4) indicates that there are either four positive roots, or two positive and two negative roots. ${ }^{23}$ The former case implies that the

\footnotetext{
${ }^{23}$ The case of four negative roots, which also gives $\operatorname{det} \mathbf{A}>0$, can be excluded given (C3).
} 
system is unstable. Because the system's characteristic polynomial, $\Pi(z)$, is a continuous function, we can rule out the case of four positive roots if we can identify some $z_{0}$ such that $z_{0}<0$ and $\Pi\left(z_{0}\right)<0$. It can be shown that various values of $z_{0}$ satisfy indeed this condition. Stability of the adjustment path is confirmed by the numerical simulations that we performed. ${ }^{24}$

The steady-state effects of the extended model are parallel to those obtained with the basic framework. Because the value of the Tobin's $q$ remains unchanged in the steady state $(\tilde{q}=1)$, the steady-state value of capital is a function of consumption only $\left(k=s(\tilde{c})\right.$ where $s^{\prime}<0$; see (39). Because of this inverse relationship between consumption and capital, the steady-state condition that determines the stock of external debt remains qualitatively unchanged and can be also reduced to be a function of consumption only $\left(D^{*}=\Lambda(\tilde{c})\right.$, where $\left.\Lambda^{\prime}<0\right)$. Finally, the steady-state value of consumption can be shown to be negatively related to a reduction in the devaluation rate, just as in Appendix B.

\footnotetext{
${ }^{24}$ The "saddlepath" is, in this case, a two-dimensional subspace of the four-dimensional space spanned by the extended model.
} 
Figure 1

Steady-State Equilibrium and Dynamic Adjustment to a Reduction in the Devaluation Rate

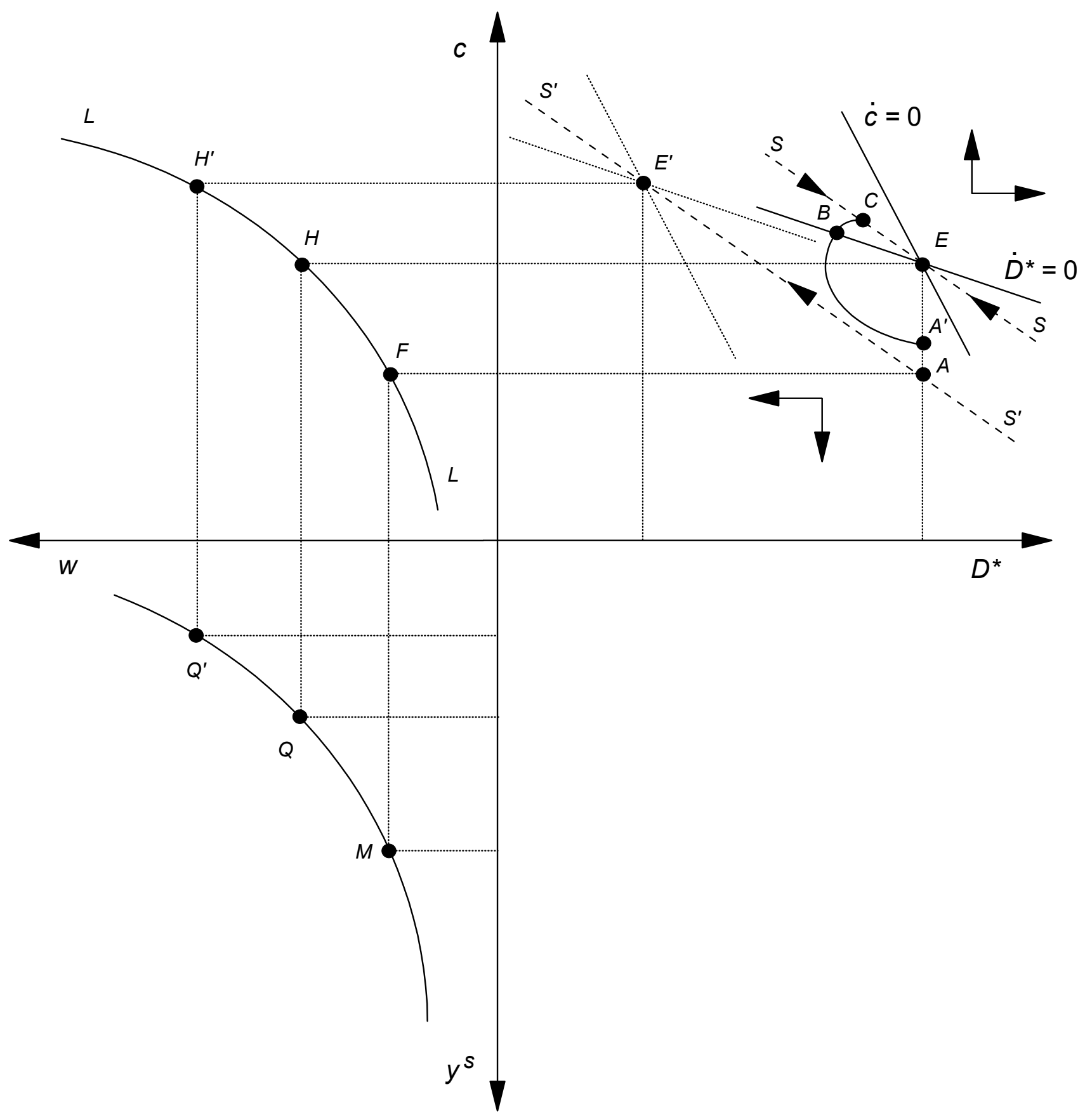




\section{Figure 2}

Permanent Reduction in the Devaluation Rate

(in percentage changes from baserun values, except for the real interest rate)
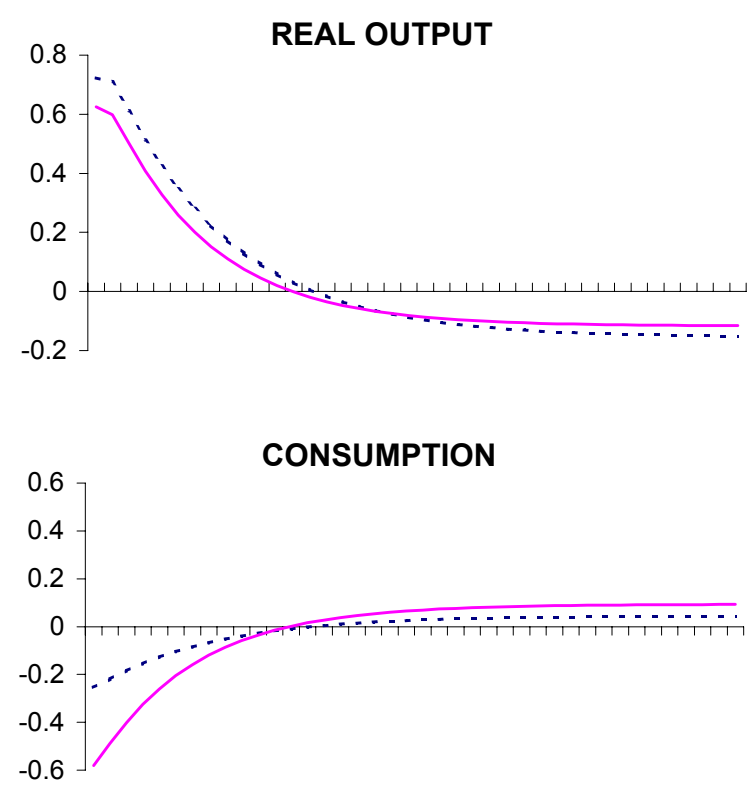

\section{LABOR SUPPLY}
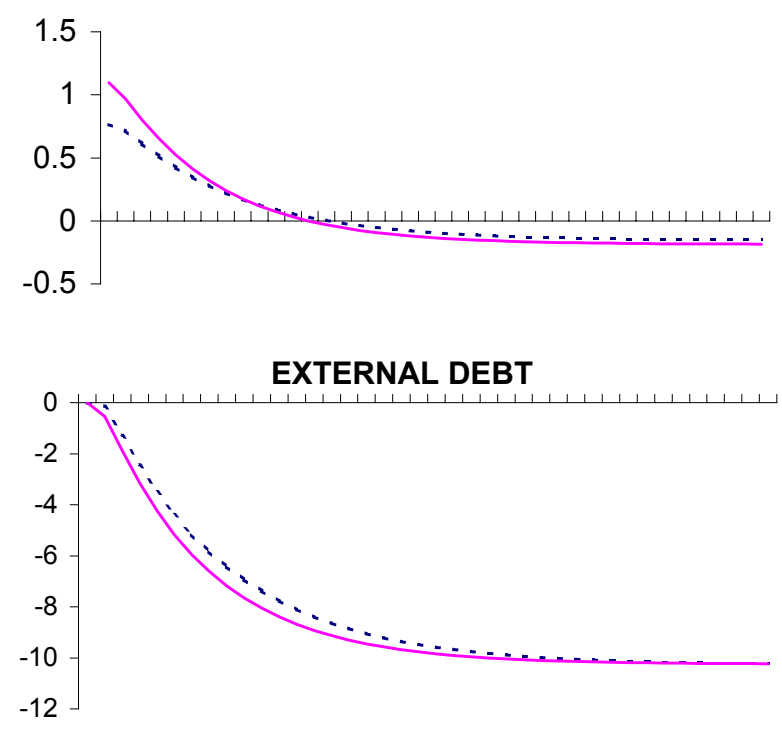

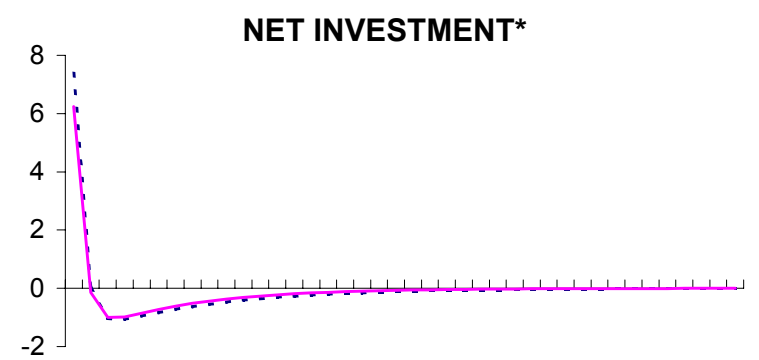

CURRENT ACCOUNT BALANCE**

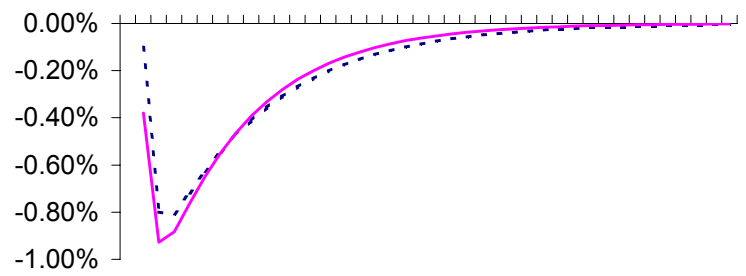

REAL INTEREST RATE***
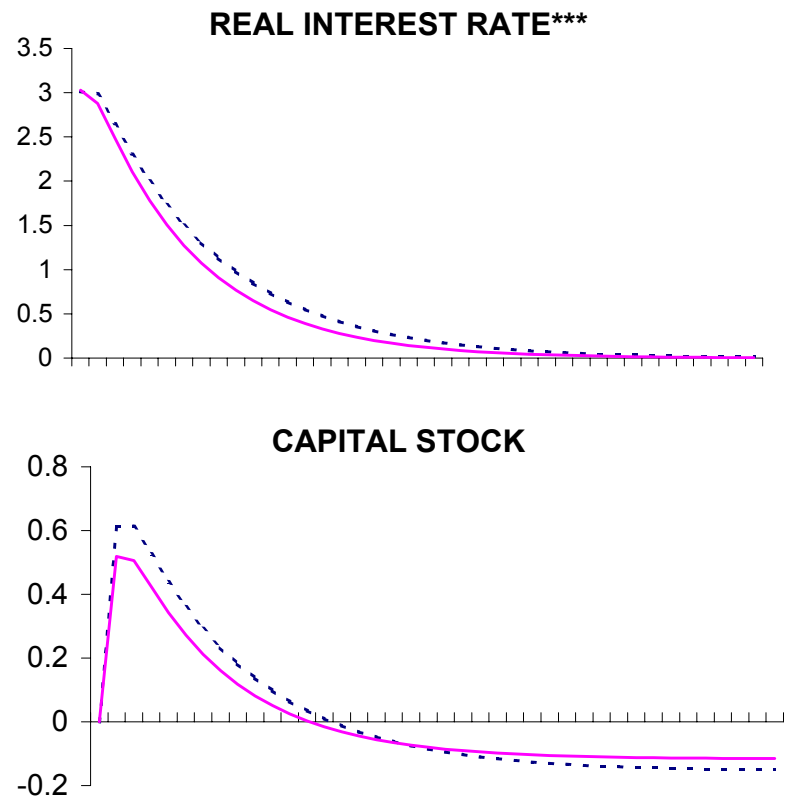

sigma $=0.8$

*In proportion of output.

${ }^{* *}$ As a share of output (percentage point changes).

${ }^{* * *}$ Percentage point changes. 


\section{Figure 3}

Temporary Reduction in the Devaluation Rate

(in percentage changes from baserun values, except for the real interest rate)
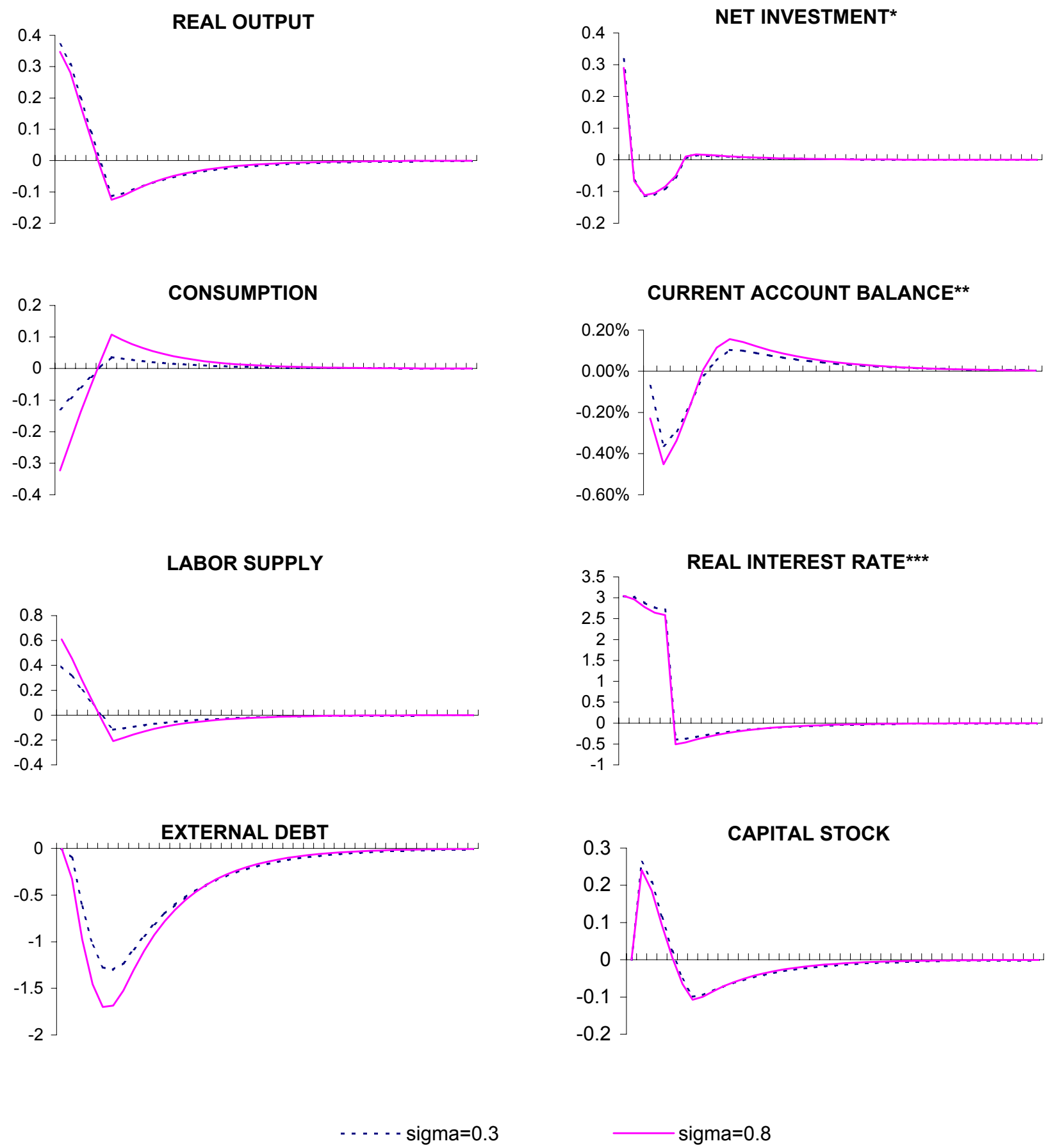

*In proportion of output.

${ }^{* *}$ As a share of output (percentage point changes).

***Percentage point changes. 